\title{
Evaluation of Oxidant-Antioxidant Status of Fluvoxamine on Human Lymphocyte Cell Culture
} \author{
Gurbuz ${ }^{5}$ iD \\ ${ }^{1}$ Ankara University, Department of Forensic Chemistry and Forensic Toxicology, Ankara, Turkey \\ ${ }^{2}$ Zonguldak Bulent Ecevit University, Department of Biochemistry, Zonguldak, Turkey \\ ${ }^{3}$ Zonguldak Bulent Ecevit University, Department of Pharmaceutical Biotechnology, Zonguldak, Turkey \\ ${ }^{4}$ Zonguldak Bulent Ecevit University, Department of Medical Biology, Zonguldak, Turkey \\ ${ }^{5}$ Ankara University, Department of Biochemistry, Ankara, Turkey
}

Suzan Muratoglu Severcan ${ }^{1}$ Cinar Severcan ${ }^{2}$ Mostafa Norizadeh Tazehkand ${ }^{3}$ Zehra Safi Oz ${ }^{4}$ Aslihan

\section{A BSTRACT}

$\mathrm{D}$ epression is one of the prevalent psychiatric diseases in Turkey and the world. Fluvoxamine is a strong selective serotonin reuptake inhibitor (SSRI) that is used as an antidepressant. No study investigating the doses of Fluvoxamine treatment that may lead to a disruption in the oxidant-antioxidant balance on the cellular level in addition to its beneficial effects has been found in the literature. For this purpose, by creating Fluvoxamine application groups at the doses of 7.5, 15, 30 and $60 \mu \mathrm{M}$ and durations of 24 and 48 hours on human lymphocyte cell cultures, we investigated the total oxidant status (TOS), total antioxidant status (TAS) and oxidative stress index (OSI). According to the results of the study, the TOS levels of all dose groups increased significantly in the 24- and 48hour applications $(\mathrm{p}<0.05)$. While the TAS levels significantly increased in the 24-hour application of the doses of 7.5 and $15 \mu \mathrm{M}$ and 48 -application of the dose of $7.5 \mu \mathrm{M}$, they significantly decreased in the 24- and 48-hour applications of the doses of 30 and $60 \mu \mathrm{M}$ $(p<0.05)$. The OSI level increased significantly in the 24 - and 48 -hour applications of the doses of 30 and $60 \mu \mathrm{M}$. The results of our study demonstrated that, in the 24 - and 48 -hour applications of the doses of 30 and $60 \mu \mathrm{M}$, the antioxidant system could not compensate and the cells exposed to oxidative stress.

\section{Keywords:}

Human lymphocyte cell culture; Total oxidant status (TOS); Total antioxidant status (TAS); Oxidative stress index (OSI); Fluvoxamine.

\section{INTRODUCTION}

D epression is one of the most prevalent psychiatric disorders, and it causes severe attacks, domestic unrest, suicidal tendencies and significant socioeconomic losses in individuals. It was reported that approximately $21 \%$ of the population worldwide is affected by depression $(1,2)$. The prevalence of depression in Turkey is approximately $10 \%$ (3). Risk factors for depression include sex, middle age, being single, low income and disability, in addition to a history of depression in the family, negative childhood experiences, other psychiatric disorders and chronic conditions like diabetes (4). The pathophysiology of depression has not been completely understood yet. It has been associated with monoaminergic neurotransmitters (serotonin, norepinephrine and dopamine) in the brain. In clinical psychiatry, distinguishing bipolar and major depression is highly important (5). The most frequently used method in the treatment of depression is prescription of antidepressant drugs (6). The usage rates of antidepressants increased between 2000 and 2010 in Europe (7). Although antidepressant use in Turkey has increased in recent years, it was reported that it is still under the OECD average of 63 doses per 1000 individuals per day as 44 doses (8).

Free radicals are molecules containing an unpaired electron in an atomic orbit. In the presence of an unpaired electron, these radicals are unstable and highly reactive. The affinity of these radicals to bond with structures like proteins, lipids, nucleic acids and enzymes is high. When free radicals bond with biomolecules that are important for the maintenance of the metabolism, they disrupt their structures. In the normal physiological process, antioxidant molecules can scavenge free radicals, but in the case that free radical production can- 
not be compensated by the antioxidant mechanism, oxidative stress develops. The increasing oxidative stress may lead to inflammation, ageing, diabetes, cardiovascular disorders and some types of cancer (9).

Fluvoxamine is a second-generation selective serotonin reuptake inhibitor (SSRI) that is used in the treatment of major depressive disorder, obsessive-compulsive disorder, anxiety and eating disorders. In the serotonin (5-hydroxytryptamine) metabolism, it specifically inhibits the reuptake of $5 \mathrm{HT}(10)$.

No study on the oxidative stress and antioxidant status of Fluvoxamine on cell cultures has been encountered in the literature. In addition to the toxic effects of drugs, it is also important to assess them in terms of dose-dependent oxidative stress and antioxidant status. This is why we aimed to examine the total oxidant status (TOS), total antioxidant status (TAS) and oxidative stress index (OSI) in human lymphocyte cultures.

\section{MATERIAL AND METHOD}

For the study, individuals who were voluntary, healthy, at close ages to each other, did not use any medication, did not use any special dietary supplement and did not smoke were selected as blood donors ( 2 female and 2 male participants at the ages of 18-25). These individuals filled out an informed consent form and voluntarily participated in the study.

This project was approved by the Clinical Studies Ethics Board of Zonguldak Bülent Ecevit University on the date of 20.06.2019 and with the protocol number of 2019$97-12 / 06$.

\section{Chemicals}

Liquid Fluvoxamine at 99\% purity was purchased from Sigma. Fig. 1 shows its chemical structure.

\section{Cell Culture}

The LD50 value was determined as $60 \mu \mathrm{M}$ by conducting a preliminary study with the method reported by Norizadeh Tazehkand and Topaktas (11). For the study, the Fluvoxamine dose groups were determined by starting with the LD50 value as $60 \mu \mathrm{M}, 30 \mu \mathrm{M}, 15 \mu \mathrm{M}$ and $7.5 \mu \mathrm{M}$ for applications of 24 and 48 hours. In addition to these, a control group on which no Fluvoxamine application was made was selected. A total of 36 cell cultures including 4 cell cultures in each group were formed. The cell cultures were formed under sterile conditions by taking $0.2 \mathrm{ml}$ of peripheral blood (1/10 heparinized) and adding it into 2.5 $\mathrm{ml}$ of chromosome medium. The cells were incubated in an incubator at $37 \pm 1^{\circ} \mathrm{C}$ for 68 hours (12). The determined Fluvoxamine doses were added to the cell cultures at the 24th and 48th hours.

\section{Biochemical Analyses}

After 68 hours, the tubes were centrifuged at $2000 \mathrm{rpm}$ for $10 \mathrm{~min}$. The supernatants were collected for TAS, TOS and OSI measurements and kept at $-80^{\circ} \mathrm{C}$.

\section{TAS Measurement}

TAS level measurement was made with a Rel Assay Diagnostics Kit (Catalog No: RL0017). The kit's method is based on the antioxidants in the sample reducing the dark blue-green ABTS radical into a colorless ABTS form. The absorbance change observed at $660 \mathrm{~nm}$ is calculated in relation to the total antioxidant level of the sample. The experiment is calibrated with a stable antioxidant standard solution that is an analog of vitamin $\mathrm{E}$ and known as the Trolox equivalent. The results are expressed as $\mu \mathrm{mol}$ / L.

\section{TOS Measurement}

TOS level measurement was made with a Rel Assay Diagnostics Kit (Catalog No: RL0024). In the kit's method, oxidants found in the sample oxidize the ferrous ionchelator complex into ferric ion. The oxidation reaction is prolonged by enhancer molecules that are abundantly present in the reaction medium. This way, the ferric ions create a colored complex with chromogenic in the acidic environment, and the total oxidant molecule amount is determined spectrophotometrically. The experiment is calibrated by hydrogen peroxide, and the results are expressed in the form of micromolar hydrogen peroxide equivalent per liter ( $\mu \mathrm{mol} \mathrm{H}_{2} \mathrm{O}_{2}$ Equiv./L).

\section{OSI Value}

The TAS and TOS units were converted into $\mu \mathrm{mol}$, and the OSI value was calculated as the percentage value of the TOS/TAS ratio.

\section{Data Analysis}

The SPSS (Statistical Package for the Social Sciences) version 25 software was used to analyze the data obtained in the study and create tables. Kruskal Wallis test was used to determine the significance levels of intergroup differences. For the significance values of $\mathrm{p}<0.05$, MannWhitney $U$ test was used to determine the significance of the difference between 2 groups. For the comparisons 
Table 1. TAS median (min-max) levels of all groups and significant difference

\begin{tabular}{llllll}
\hline $\begin{array}{c}\text { Fluvoksamin } \\
\text { administration }\end{array}$ & $n$ & $\begin{array}{c}\text { Exposing time } \\
\text { (hours) }\end{array}$ & $\begin{array}{c}\text { TAS } \\
(\mathrm{mmol} / \mathrm{L})\end{array}$ & p value \\
\hline Control & 4 & none & $0,22(0,2-0,25)$ & - \\
$7,5 \mu M$ & 4 & 24 & $0,26(0,21-0,28)$ & 0,144 \\
$15 \mu M$ & 4 & 24 & $0,34(0,31-0,38) *$ & 0,021 \\
$30 \mu M$ & 4 & 24 & $0,08(0,03-0,08) * 0,020$ \\
$60 \mu M$ & 4 & 24 & $0,07(0,06-0,09) *$ & 0,020 \\
$7,5 \mu M$ & 4 & 48 & $0,24(0,17-0,29)$ & 1 \\
$15 \mu M$ & 4 & 48 & $0,35(0,21-0,39)$ & 0,110 \\
$30 \mu M$ & 4 & 48 & $0,08(0,03-0,09) *$ & 0,021 \\
$60 \mu M$ & 4 & 48 & $0,07(0,03-0,09) *$ & 0,021 \\
\hline n:number of cell culture, significant difference compare to Group 1 & &
\end{tabular}

between 2 groups, $\mathrm{p}<0.05$ was accepted as statistically significant. To examine the correlations between the parameters, Spearman's correlation analysis was conducted between the non-normally distributed groups.

\section{RESULTS}

The significance of the difference among all groups in terms of the TAS, TOS and OSI values was determined (respectively, $\mathrm{p}=0.000, \mathrm{p}=0.000, \mathrm{p}=0.001$ ).

The TAS levels of the groups in comparison to the control did not differ significantly in 24-hour application of $7.5 \mu \mathrm{M}$ dose and 48-hour applications of $7.5 \mu \mathrm{M}$ and $15 \mu \mathrm{M}$ doses while an significantly increase was measured in the 24-hour application of the $15 \mu \mathrm{M}$ dose. However, the groups of 24- and 48-hour applications of the 30 and $60 \mu \mathrm{M}$ doses significantly decreased in comparison to the control (Table 1 and Fig. 1).

The TOS levels of the groups increased significantly in comparison to the control in the 24- and 48-hour applications of all doses (Table 2 and Fig. 2).

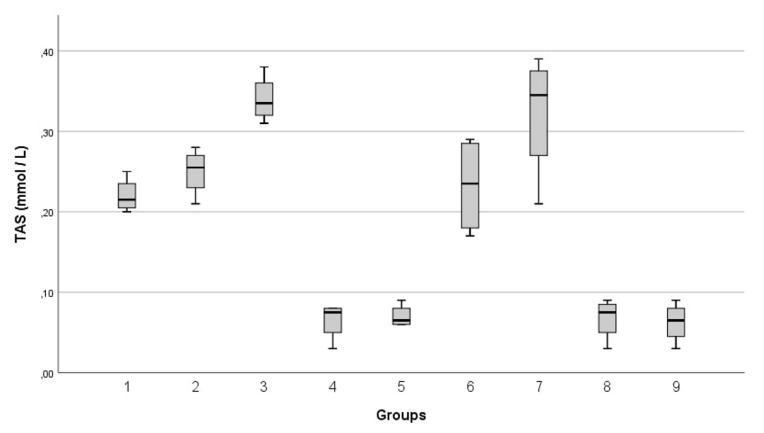

Figure 1. The TAS levels of groups
Table 2. TOS median (min-max) levels of all groups and significant difference

\begin{tabular}{lllll}
\hline $\begin{array}{c}\text { Fluvoksamin ad- } \\
\text { ministration }\end{array}$ & $n$ & $\begin{array}{c}\text { Exposing } \\
\text { time } \\
\text { (hours) }\end{array}$ & $\begin{array}{c}\text { TOS } \\
(\mu \mathrm{mol} / L)\end{array}$ & p value \\
\hline Control & 4 & none & $1,04(0,87-1,20)$ & - \\
$7,5 \mu M$ & 4 & 24 & $1,34(1,15-1,42) *$ & 0,043 \\
$15 \mu M$ & 4 & 24 & $1,69(1,47-1,95) *$ & 0,021 \\
$30 \mu M$ & 4 & 24 & $1,8(1,62-1,91) *$ & 0,021 \\
$60 \mu M$ & 4 & 24 & $1,87(1,63-2,09) *$ & 0,021 \\
$7,5 \mu M$ & 4 & 48 & $1,25(1,22-1,28) *$ & 0,021 \\
$15 \mu M$ & 4 & 48 & $1,48(1,31-1,72) *$ & 0,021 \\
$30 \mu M$ & 4 & 48 & $1,8(1,78-2,1) *$ & 0,021 \\
$60 \mu M$ & 4 & 48 & $2,13(1,9-2,3) *$ & 0,021 \\
\hline n:number of cell culture, *significant difference compare to Group 1 &
\end{tabular}

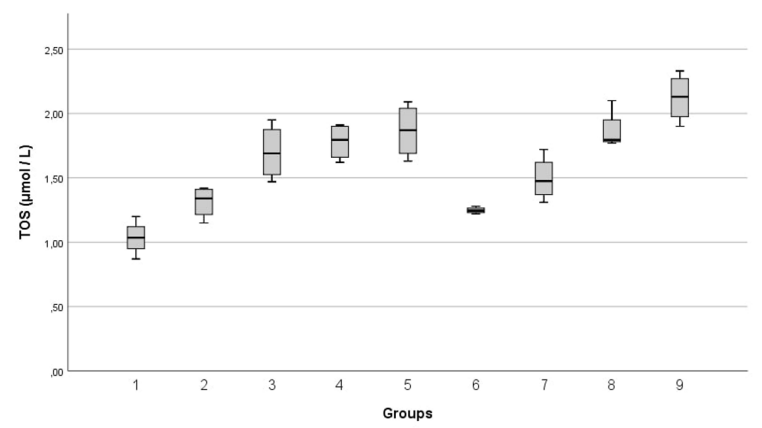

Figure 2. The TOS levels of groups

Table 3. OSI median (min-max) levels of all groups and significant difference

\begin{tabular}{lcccc}
\hline $\begin{array}{c}\text { Fluvoksamin ad- } \\
\text { ministration }\end{array}$ & $n$ & $\begin{array}{c}\text { Exposing } \\
\text { time } \\
\text { (hours) }\end{array}$ & OSI & p value \\
\hline Control & 4 & none & $0,47(0,41-0,55)$ & - \\
$7,5 \mu M$ & 4 & 24 & $0,53(0,51-0,55)$ & 0,386 \\
$15 \mu M$ & 4 & 24 & $0,51(0,42-0,58)$ & 0,386 \\
$30 \mu M$ & 4 & 24 & $2,43(2,03-6,3) *$ & 0,021 \\
$60 \mu M$ & 4 & 24 & $2,78(1,94-3,48) *$ & 0,021 \\
$7,5 \mu M$ & 4 & 48 & $0,55(0,44-0,74)$ & 0,248 \\
$15 \mu M$ & 4 & 48 & $0,44(0,42-0,62)$ & 0,564 \\
$30 \mu M$ & 4 & 48 & $2,62(1,97-6) *$ & 0,021 \\
$60 \mu M$ & 4 & 48 & $3,52(2,28-6,33) *$ & 0,021 \\
\hline n:number of cell culture, *significant difference compare to Group 1 &
\end{tabular}

The difference in the OSI levels in comparison to the control was not significant in the 24- and 48-hour Fluvoxamine applications at the doses of 7.5 and $15 \mu \mathrm{M}$. In the 24- and 48-hour applications of the 30 and $60 \mu \mathrm{M}$ doses, the 


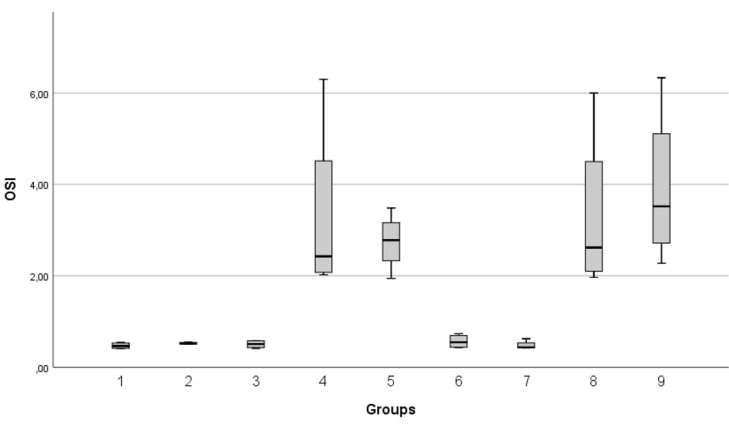

Figure 3. The OSI levels of groups

Table 4. Correlation among parameters

\begin{tabular}{|c|c|c|c|c|}
\hline \multicolumn{2}{|c|}{$\begin{array}{c}\text { Fluvoksamin } \\
\text { nistration }\end{array}$} & TAS & TOS & OSI \\
\hline \multirow{3}{*}{ TAS } & rvalue & 1 & $-0,514$ & $-0,906$ \\
\hline & & & & \\
\hline & $p$ value & - & $0,001 * *$ & $0,000 * *$ \\
\hline \multirow{2}{*}{ TOS } & rvalue & $-0,514$ & 1 & 0,743 \\
\hline & $p$ value & $0,001 * *$ & - & $0,000 * *$ \\
\hline \multirow{2}{*}{ OSI } & rvalue & $-0,906$ & 0,743 & 1 \\
\hline & $p$ value & $0,000 * *$ & $0,000 * *$ & - \\
\hline
\end{tabular}

** Correlation is significant at the 0,01 (2-tailed)

OSI levels of the groups significantly increased when compared to the control (Table 3 and Fig. 3).

The results of the Spearman's correlation analysis are given in Table 4.

Accordingly, there were negative correlations between the TAS and TOS levels (Fig. 4) and between the TAS and OSI levels (Fig. 5) $(\mathrm{p}<0.01)$ and a positive correlation between the TOS and OSI levels ( $<<0.01)$ (Fig. 6).

\section{DISCUSSION}

Depression is a high-prevalence disease that reduces functional capacity and quality of life and causes comorbidities and mortalities. With the increasing number of cases in the last decade, many studies have been conducted, and new treatment methods have been developed. There are several different antidepressants that have been shown to be effective in randomized studies (12). Fluvoxamine is an antidepressant drug which is a strong SSRI. It is a highly lipophilic compound, in enters the cell fast and is used in the treatment of anxiety, bipolar disorder, obsessive-compulsive disorder and especially major depression (13).

An increase in reactive oxygen species (ROS) may be scavenged in the cellular physiological process by main an-

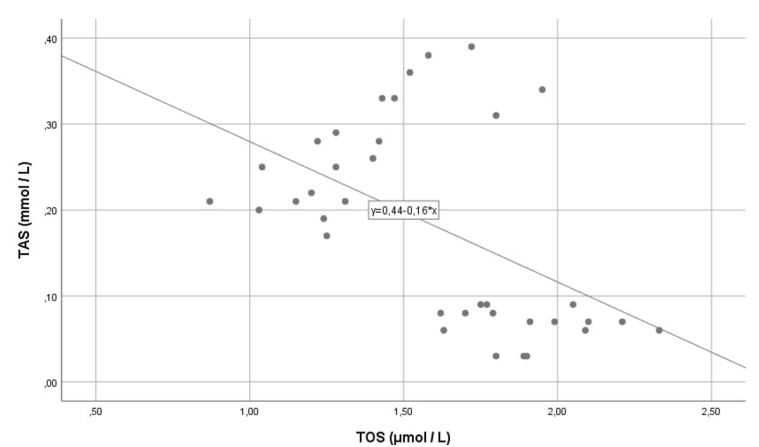

Figure 4. The correlation between TAS and TOS

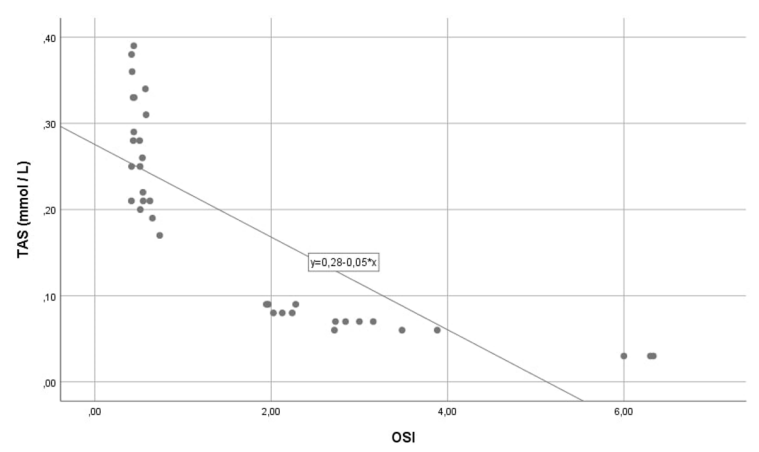

Figure 5. The correlation between TAS and OSI

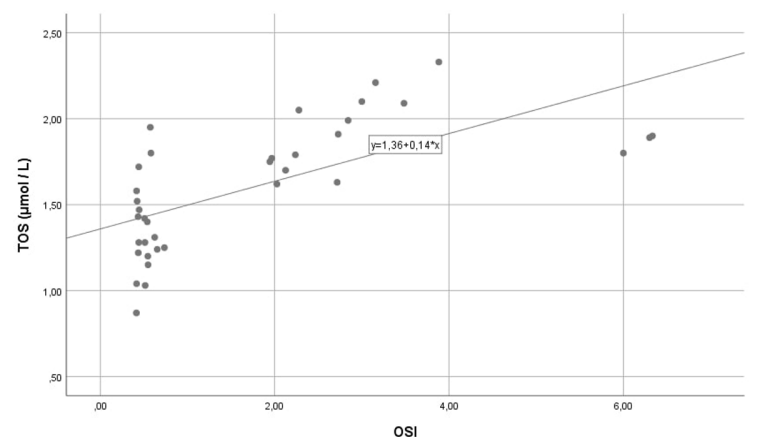

Figure 6. The correlation between TOS and OSI

tioxidant system enzymes such as superoxide dismutase (SOD), catalase and glutathione peroxidase. By interacting with the biomolecules of cells such as lipids, proteins and nucleic acids, ROS may disrupt the natural structures of these molecules (14). With the method they developed, Erel proposed the measurement of TOS products rather than showing the oxidation products of lipids, proteins and DNA (15). They also proposed measuring the total antioxidant capacity rather than measuring different antioxidant molecules separately (16). They reported that it will be meaningful to interpret oxidative stress by calculating the percentage ratio of TOS/TAS $(15,16)$.

İstifli et al. demonstrated that administration of Sertraline, which is an SSRI used as an antidepressant, on human lymphocyte cell cultures by LD50 $(5 \mu \mathrm{g} / \mathrm{mL})$ and $3.75 \mu \mathrm{g} / \mathrm{mL}$ for 24 and 48 hours and observed as a result that TOS and 
OSI increased significantly (17). In the experimental animal models on which they applied lipopolysaccharides, AbdelSalem et al. observed that, with Fluvoxamine treatment, oxidative stress decreased, and antioxidant molecules were increased in liver and brain tissues (18).

Although it has been reported that Fluvoxamine reduces oxidative stress and triggers the antioxidant system as a treatment, it is needed to know its doses that may disrupt the oxidant-antioxidant balance by contact with cells. According to the results of our study, it was observed that the TOS level significantly increased in the 24- and 48-hour applications of the included Fluvoxamine doses $(\mathrm{p}<0.05)$. As the dose increased in the groups, the mean and median values also increased. Considering the TAS levels of the dose groups, significant increases in the 24-hour applications of the 7.5 and $15 \mu \mathrm{M}$ doses and the 48-hour application of the $7.5 \mu \mathrm{M}$ dose $(\mathrm{p}<0.05)$, as well as an insignificant increase in the 48-hour application of the $15 \mu \mathrm{M}$ dose, were observed. This situation indicates that, as a response to the increasing TOS, the cellular antioxidant system was induced. Despite this, the TAS levels significantly decreased in the 24- and 48-hour applications of the 30 and $60 \mu \mathrm{M}$ doses $(\mathrm{p}<0.05)$. The results demonstrate that, at the doses of 30 and $60 \mu \mathrm{M}$, the cellular antioxidant system is disrupted against the increasing reactive oxygen species. The finding that clarifies this situation best is the OSI levels of the groups. The OSI level significantly increased in the 24- and 48-hour applications of the 30 and $60 \mu \mathrm{M}$ doses $(\mathrm{p}<0.05)$. Although there was a significant increase in the TOS levels in the 24- and 48-hour applications of the 7.5 and $15 \mu \mathrm{M}$ doses, there was no significant change in the OSI levels. These findings demonstrate that the cell was protected from oxidative stress with the increase in the antioxidant system as a response to the increase in ROS in the 24- and 48-hour applications of the 7.5 and $15 \mu \mathrm{M}$ doses. According to our correlation analysis results, this significant relationship was also demonstrated by the pairwise comparisons of the TAS, TOS and OSI values.

\section{CONCLUSION}

The results of our study showed that, although the antioxidant system was able to scavenge the increased reactive oxygen species in the 24- and 48-hour applications of the 7.5 and $15 \mu \mathrm{M}$ doses of Fluvoxamine which is used in depression treatment on the created human lymphocyte cell cultures, in the 24- and 48-hour applications of the 30 and $60 \mu \mathrm{M}$ doses, this oxidative status could not be compensated by the antioxidant system, and the cells were subjected to oxidative stress.

The findings of our study clearly showed the doses of Fluvoxamine at which there would be oxidative stress on the cellular level. We believe that these results will provide a significant insight into protection of public health by making an important contribution to the literature.

\section{References}

1. Möller HJ, Bitter I, Bobes J, Fountoulakis K, Höschl C, Kasper S. Position statement of the European Psychiatric Association (EPA) on the value of antidepressants in the treatment of unipolar depression. European Psychiatry 27(2) (2012) 114-128.

2. Gadassi R, Mor N. Confusing acceptance and mere politeness: Depression and sensitivity to Duchenne smiles. Journal of Behavior Therapy and Experimental Psychiatry 50 (2016) 8-14.

3. Açıkgöz A, Dayı A, Binbay T. Üniversitede okuyan kız öğrencilerde depresyon prevalansı ve ilişkili faktörler. Cukurova Medicine Journal 43(1) (2018) 131-140.

4. Semenkovich K, Brown ME, Svrakic DM, Lustman PJ. Depression in type 2 diabetes mellitus: prevalence, impact, and treatment. Drugs 75(6) (2015) 577-587.

5. Casey DA. Depression in Older Adults: A Treatable Medical Condition. Primary Care 44(3) (2017) 499-510.

6. Yüzbaşığlu D, Avuloğlu Yılmaz E, Ünal F. Antidepresan ilaçlar ve genotoksisite. TÜBAV Bilim Dergisi 9(1) (2016) 17-28.

7. Gusmão R, Quintão S, McDaid D, Arensman E, Audenhove CA, Coffey C, Värnik C, Värnik P, Coyne J, Hegerl U. Antidepressant Utilization and Suicide in Europe: An Ecological Multi-National Study. PLoS One 8(6) (2013) e66455.

8. Health at a Glance 2019 : OECD Indicators. https://www. oecd-ilibrary.org/sites/43146d 4b-en/index.html?item Id =/ content/component/43146d4b-en, 20.02.2021, https://doi. org/10.1787/888934018089.

9. Lobo V, Patil A, Phatak A, Chandra N. Free radicals, antioxidants and functional foods: Impact on human health. Pharmacognosy Reviews 4(8) (2010) 118-126.

10. Otter J, McIntyre IM, Morhaime J, Cantrell L. A fluvoxaminerelated fatality: Case report with postmortem concentrations. Forensic Science International 300 (2019) e31-e33.

11. Norizadeh Tazehkand $M$, Topaktas $M$. The in vitro genotoxic and cytotoxic effects of remeron on human peripheral blood lymphocytes. Drug and Chemical Toxicology. 38(3) (2015) 266-271.

12. Cuijpers P, Quero S, Dowrick C, Arroll B. Psychological Treatment of Depression in Primary Care: Recent Developments. Current Psychiatry Reports 21(12) (2019) 129.

13. Hashimoto K. Activation of sigma-1 receptor chaperone in the treatment of neuropsychiatric diseases and its clinical implication. Journal of Pharmacological Sciences 127(1) (2015) 6-9.

14. Rogrigo R. Oxidative stress and antioxidants: their role in human disease. Nova Science Publishers, pp. 2-18, New York, 2009.

15. Erel O. A new automated colorimetric method for measuring total oxidant status. Clinical Biochemistry 38 (2005) 1103-1111.

16. Erel O. A novel automated direct measurement method for total antioxidant capacity using a new generation, more stable ABTS radical cation. Clinical Biochemistry 37 (2004) 277- 285.

17. Istifli ES, Çelik R, Hüsunet MT, Çetinel N, Demirhan O, Ila HB. In vitro cytogenotoxic evaluation of sertraline. Interdisciplinary Toxicology 11(3) (2018) 181-188.

18. Abdel-Salam OME, Morsy SMY, Sleem AA. The effect of different antidepressant drugs on oxidative stress after lipopolysaccharide administration in mice. Experimental Clinical Science Journal 10 (2011) 290-302. 